\title{
BETONDA CFRP SARGI UYGULAMASININ DENEYSEL VE ANALİTIK OLARAK KARŞILAŞTIRILMASI
}

\author{
İlker USTABAȘ ${ }^{*}$, Ali GÜRBÜZ ${ }^{1}$, Zafer KURT ${ }^{1}$, Fatih DEȘíK ${ }^{2}$ \\ ${ }^{1}$ Recep Tayyip Erdoğan Üniversitesi, Mühendislik ve Mimarlık Fakültesi, İnşaat Mühendisliği Bölümü, Rize, \\ Türkiye \\ ${ }^{2}$ DSİ 182. Şube Müdürlüğü, Merkez, Burdur, Türkiye
}

\begin{tabular}{|c|c|}
\hline Anahtar Kelimeler & Öz \\
\hline $\begin{array}{l}\text { CFRP, } \\
\text { Karbon Elyaf, } \\
\text { Güçlendirme, } \\
\text { CFRP Modelleme, } \\
\text { Ansys. }\end{array}$ & $\begin{array}{l}\text { Karbon fiber takviyeli kumaşlar (CFRP) gibi çeşitli polimer kompozitlerin deprem } \\
\text { dayanımı yetersiz yapları güçlendirilmesinde kullanımı yaygınlaşmaktadır. Bu } \\
\text { yeni güçlendirme yöntemi sargı etkisiyle betonarme elemanların basınç } \\
\text { dayanımını artırırken sünek davranışa da önemli ölçüde katkı sağlamaktadır. Bu } \\
\text { çalışma kapsamında; mevcut bir yapıdan karot numuneler alınmıştır. Bu karot } \\
\text { numuneler CFRP ile sarılarak güçlendirilmiş ve basınç dayanımları ölçülmüştür. } \\
\text { Aynı zamanda karot numuneler ANSYS yazılımıyla bilgisayar ortamında } \\
\text { modellenerek bu model üzerinden teorik basınç dayanımları hesaplanmış ve bu } \\
\text { teorik değerlerin deneysel dayanımlarla kıyaslanması yapılmıştır. Elde edilen } \\
\text { teorik ve den eysel basınç dayanımları konuya ilişkin literatürle karşlaştırılmıştır. } \\
\text { Bu çalışma sonucunda tek kat ve iki kat CFRP sarılarak güçlendirilen numunelerin } \\
\text { gerilme deformasyon sonuçları literatürdeki çalışmalarla örtüșen sonuçlar elde } \\
\text { edilmiştir. Deneysel ve teorik değerlerin birbiriyle uyumlu olduğu bir modelleme } \\
\text { yaklaşımı ortaya koyulmuștur. }\end{array}$ \\
\hline
\end{tabular}

\section{EXPERIMENTAL AND ANALYTICAL COMPARISON OF CFRP CONFINEMENT} APPLICATION ON CONCRETE

\begin{tabular}{ll}
\hline Keywords & Abstract \\
\hline CFRP, & The use of various polymer composites such as carbon fiber reinforced fabrics \\
Strengthening, & (CFRP) in strengthening structures with insufficient earthquake resistance is \\
CFRP Modelling, & becoming widespread in the building industry. While this new reinforcement \\
Ansys. & method increases the tensile strength of reinforced concrete structural elements \\
& with the effect of winding, it also contributes significantly to ductile behavior. In \\
& this study, core samples were taken from a structure with a lower strength than \\
the target strength. These core samples were reinforced by wrapping them with & CFRP and their compressive strength was measured. At the same time, core \\
& samples were modeled in computer environment with ANSYS software, and \\
& theoretical compressive strengths were calculated on this model and comparison \\
& of these theoretical values with experimental strengths. The theoretical and \\
experimental compressive strengths obtained were compared with the relevant & literature. In this study, stress deformation results of the samples reinforced by \\
wrapping single layer and two layers of CFRP were obtained that overlap with \\
studies in the literature. A modeling approach in which experimental and \\
theoretical values are compatible with each other has been introduced.
\end{tabular}

Alıntı / Cite

Ustabaş, İ., Gürbüz, A., Kurt, Z., Deşik, F., (2020). Betonda CFRP Sargı Uygulamasının Deneysel ve Analitik Olarak Karşılaştırılması, Mühendislik Bilimleri ve Tasarım Dergisi, 8(3), 921-930.

\begin{tabular}{l|l|l}
\hline Yazar Kimliği / Author ID (ORCID Number) & Makale Süreci / Article Process \\
\hline İ. Ustabaș, 0000-0003-0473-2543 & Başvuru Tarihi / Submission Date & 07.08 .2020 \\
A. Gürbüz, 0000-0003-1123-9968 & Revizyon Tarihi / Revision Date & 25.08 .2020 \\
Z. Kurt, 0000-0002-4948-6318 & Kabul Tarihi / Accepted Date & 15.09 .2020 \\
F. Deşik. 0000-0001-5035-1894 & Yayım Tarihi / Published Date & 24.09 .2020 \\
\hline
\end{tabular}

\footnotetext{
* ilgili yazar / Corresponding author: ilker.ustabas@erdogan.edu.tr, +90-464-223-7518/1224
} 


\section{Giriş (Introduction)}

Türkiye'deki yapı stokunun ve nüfus yoğunluğunun önemli bir kısmı deprem tehdidi altındadır. Türkiye'de yapılan birçok bilimsel çalışma, mevcut yapıların önemli bir kısmının depreme hazır olmadığını ve güçlendirilmeye ihtiyaç duyduğunu göstermektedir (Ustabas, 2012; Kurt ve Ateş, 2019; Gurbuz ve Tekin, 2017);(Dilmaç vdig., 2018); (Dilmaç, H., 2020); (Tekeli vdig., 2020). Tehlike altındaki çok sayıda yapının kısa sürede güçlendirilebilmesi için etkili ve hızlı uygulanabilir yöntemlere ihtiyaç vardır. Bu amaçla yapıların depreme karşı güçlendirilmesine ilişkin çok sayıda malzeme ve yöntem geliştirilmiş ve halen geliştirilmektedir (Ustabaş ve Deşik, 2020; Baki vd., 2020.; Mirmiran ve Shahawy, 1997). Lifli polimer kompozitler (FRP) de literatürde yapı güçlendirme amacıyla sıkça kullanılan bu malzemeler arasında gösterilmektedir (Eid ve Paultre; 2017.; Çelik ve Karaşin, 2014). FRP'ler son derece hafif bir malzeme olmaları ve şantiye sahasında uygulama kolaylığı gibi avantajları nedeniyle yapı güçlendirmelerinde tercih edilmeleri artmaktadır. İnce tabakalar şeklinde kullanılmasına karşın çok yüksek çekme dayanımına sahip olmaları özellikle betonarme elemanlar için FRP'yi bir kat daha önemli kılmaktadır (Lee vd., 2017.; İlki vd., 2003). Betonarme yapı elemanları genellikle santimetre ve metre ile ölçülür boyutlardadır. Milimetre düzeyindeki farklar sıva ve boya ile değișebilen tolerans sınırları içerisinde kalmaktadır (Karasin vd., 2010). Böylelikle FRP ile yapılan güçlendirmelerde eleman boyutları neredeyse hiç değişmemektedir. Bu da önemli bir avantajdır. Bunun yansıra betonun en büyük eksiği olan çekme dayanımındaki yetersizlikleri bertaraf etmek için FRP sargılama yönteminin başarılı sonuçlar verdiği literatürde yapılan sayısız araştırma ile doğrulanmaktadır (Karasin vd., 2010., İlki vd., 2008., Mert ve Elmas, 2007). FRP malzemeler kullanılarak güçlendirilen yapı elemanlarının hem basınç kapasiteleri hem de süneklik değerleri kolaylıkla artırılabilmektedir (Vincet ve Ozbakkaloglu, 2016.; Mirmiran ve Shavy, 1997). İlgili literatür incelendiğinde; tüm araştırmacılar FRP kompozitlerin yapı elemanlarının performansına önemli ölçüde katkı yaptığı konusunda hemfikirdirler (Lee vd., 2017; Yin vd., 2016.; Ozbakkaloglu ve Lim, 2013; Seffo ve Hamcho, 2012.; Xiao ve Wu, 2003).

Gelişen beton teknolojisiyle birlikte inşaat mühendisliğinde madencilikten ulaşıma bir çok yeni alan açılmıştır (Hiçyılmaz ve Özçelik, 2019). Beton teknolojisindeki gelişmelerle birlikte hızla artan beton dayanımları süneklik sorununa çözüm arayıșlarını da beraberinde getirmektedir (Sarıbıyık, 2017). Genel olarak yüksek dayanımlı betonların kullanıldığı yapılar, geleneksel betonların kullanıldı̆̆ı yapılardan daha gevrek bir davranıș sergilemektedir. Fiber takviyeli polimerlerle bu soruna da çözüm sunulabilir (Stolla vd., 2000). Yüksek dayanımlı beton kullanılan yapı elemanları fiber takviyeli polimerlerle dıștan sarılarak gevreklik sorunu çözülebilmektedir. Bu noktada sıkça tercih edilen polimerlerin başında karbon lif takviyeli olan kumaşlar gelmektedir. Karbon liflerle güçlendirilmiş polimerler (CFRP) FRP kompozitlerin bir çeşididir (Turgay vd., 2010). Çelikten daha yüksek elastisite modülüne sahip bu malzemenin dıştan sargılanmasıyla betonarme eleman süneklik kazanırken betonun çekme dayanımındaki zafiyet de telafi edilebilmektedir.

Bu çalışmada, hedeflenen dayanım sınıfından düşük kalan bir yapının betonunun CFRP ile bir kat ve iki kat olarak sarılarak beton basınç dayanımlarının artırılması hedeflenmiştir. Çalışma kapsamında mevcut yapıdan karot numuneler alınarak, karot numunelerde ve CFRP sargılı karot numunelerde basınç dayanımları ölçülmüştür. Laboratuvarda deneye tabi tutulan betonlar ANSYS yazılım programıyla modellenerek bilgisayar programından da dayanımları hesaplanmıştır. Deneysel basınç dayanımlarıyla teorik basınç dayanımları kıyaslanmıştır. Böylelikle bu çalışma ile uygulanan model üzerinden araştırmacıların deneysel olarak uzun uğraşlarla elde ettikleri verilerin bir bilgisayar programı üzerinden daha çok miktarda ve türde veri elde etmesine imkan sağlanacaktır.

\section{Materyal ve Yöntem (Material and Method)}

Bu çalışmada Ferhatlı - Gümüşhane Köy Yolu İnşaatı İncesu Köprüsü kolonlarından 9 adet karot numunesi alınmıştır. Karot numunelerinin anma çapı 100 mm'dir. Numune boyutları ayrıntılı olarak Tablo 5'de verilmiştir. Karotlar kükürt grafit karışımı ile başlıklanmışlardır. Karot numunelerinin üç tanesi sargısız olarak, üç tanesi bir kat CFRP sargılı olarak ve üç tanesi iki kat CFRP sargılı olarak TS EN 12390-3'e göre basınç dayanımları ölçülmüştür.

\section{1. Çalışmada Kullanılan Malzeme Özellikleri (Material Properties Used in Study)}

Bu çalışmada karot numune alınan köprü kolon betonlarında CEM I 42,5 R sınıfı çimento kullanılmıştır. Köprü kolonlarında kullanılan betona ait karışıma giren malzemeler ve karışım oranları Tablo 1'deki gibidir. 
Tablo 1. Deneysel Çalışmada Kullanılan Beton Karışım Malzemeleri (Concrete Mixed Materials Used Experimental Study)

\begin{tabular}{|c|c|c|c|c|c|c|c|c|c|c|}
\hline $\begin{array}{l}\text { Cimento } \\
\text { Dozajı }\end{array}$ & Su & \multicolumn{2}{|c|}{ S/C } & \multicolumn{2}{|c|}{ Kimyasal Katkı } & \multicolumn{2}{|c|}{$\mathbf{1 2 - 2 5} \mathbf{~ m m}$} & \multicolumn{2}{|c|}{$\mathbf{5 - 1 2} \mathbf{~ m m}$} & \multicolumn{2}{|c|}{ 0-5 mm } \\
\hline $\mathrm{kg}$ & $\mathrm{kg}$ & & $\mathrm{kg}$ & $\%$ & $\mathrm{~kg}$ & $\%$ & $\mathrm{~kg}$ & $\%$ & $\mathrm{~kg}$ & $\%$ \\
\hline 350 & 187 & 0.53 & 4.2 & 1.2 & 496.7 & 28 & 372.5 & 21 & 904.6 & 51 \\
\hline
\end{tabular}

Beton karışımda süper akışkanlaştırıcı kimyasal katkı kullanılmıştır. Betonda kullanılan agrega tane büyüklüğüne göre, bağll yoğunluğu, su emme, ince madde oranı, incelik modülü ve metilen mavisi değerleri Tablo 2'de görülmektedir.

Tablo 2. Betonda kullanılan agregaya ait fiziksel özellikler (Physical Properties of Aggregate Used in Concrete)

\begin{tabular}{|c|c|c|c|c|c|}
\hline $\begin{array}{c}\text { Agrega ebadı } \\
(\mathrm{mm})\end{array}$ & $\begin{array}{c}\text { Bağıl yoğunluk } \\
\left(\mathrm{kg} / \mathrm{dm}^{3}\right)\end{array}$ & $\begin{array}{c}\text { Su emme } \\
(\%)\end{array}$ & $\begin{array}{c}\text { İnce madde } \\
\text { oranı }(\%)\end{array}$ & $\begin{array}{c}\text { İncelik } \\
\text { modülü }\end{array}$ & $\begin{array}{c}\text { Metilen } \\
\text { mavisi }\end{array}$ \\
\hline $12-25$ & 2,66 & 1,6 & 0,6 & - & - \\
\hline $5-12$ & 2,62 & 1,9 & 0,9 & - & - \\
\hline $0-5$ & 2,60 & 2,5 & 8,7 & 3,1 & 1,0 \\
\hline
\end{tabular}

Beton dizaynında kullanılan agrega granülometrisi Şekil 1'de görülmektedir. Şekil 1'deki agreganın maksimum tane çapı 31,5 mm'dir. Karışım agregasının granülometrisi kesikli çizgi olarak Şekil 1'de görülmektedir.

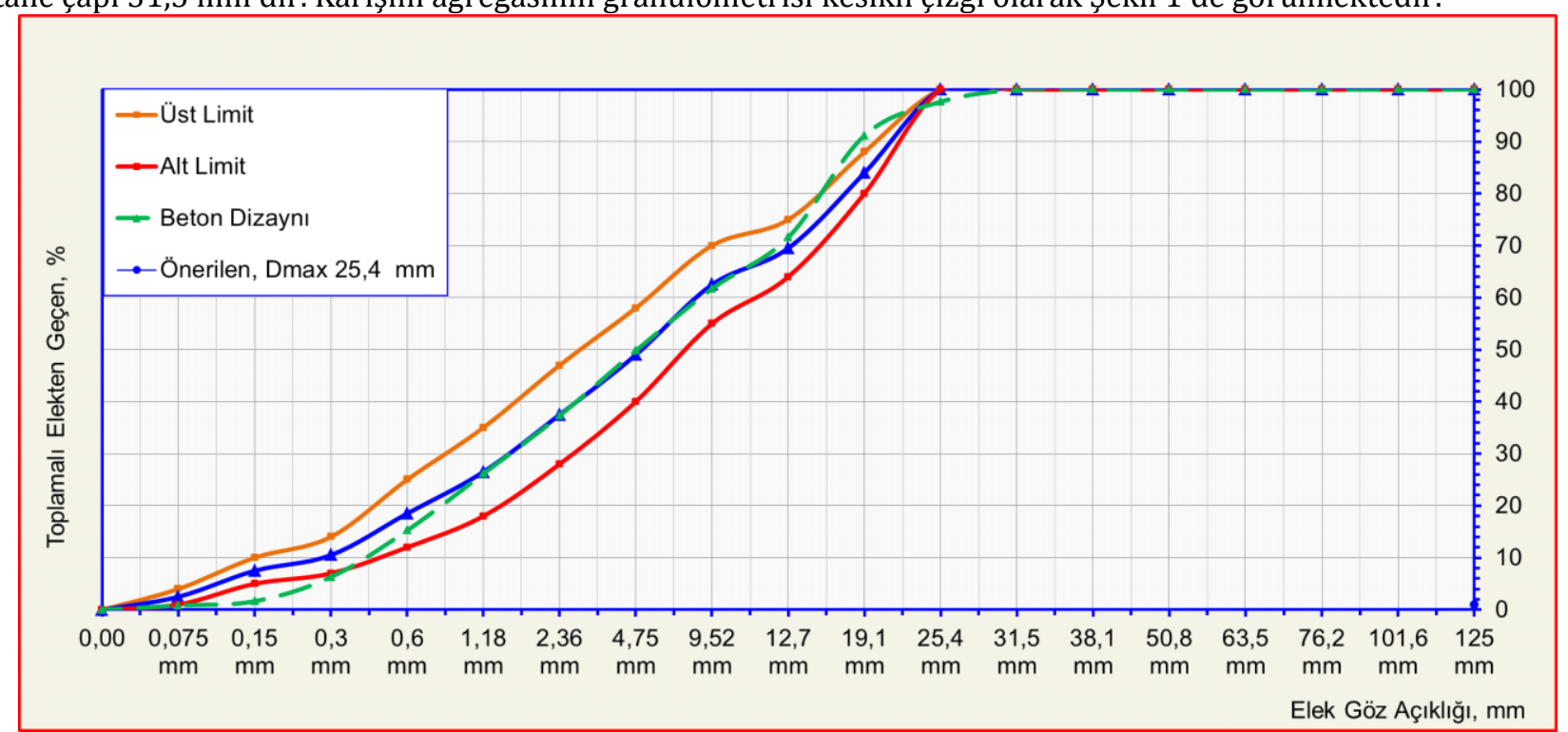

Şekil 1. Beton dizaynında kullanılan agrega granülometrisi (Aggregate Granulometry Used in Concrete Design)

Numuneleri güçlendirmek için kullanılan CFRP kumaş ve epoksi setinin üretici tarafından bildirilen özellikleri Tablo 3'de verilmiștir.

Tablo 3. CFRP Kumaș ve Epoksinin Malzeme Özellikleri (Material Properties of CFRP Fabric and Epoxy)

\begin{tabular}{|l|l|l|}
\hline & CFRP & Epoksi \\
\hline Yoğunluk & $1850 \mathrm{~kg} / \mathrm{m}^{3}$, & $1300 \mathrm{~kg} / \mathrm{m}^{3}$, \\
\hline Çekme dayanımı & $4200 \mathrm{MPa}$. & $50 \mathrm{MPa}$ \\
\hline Elastisite modülü & $240000 \mathrm{MPa}$ & $3800 \mathrm{MPa}$ \\
\hline Kopma uzaması : & $\% 1.8$ & $\% 0.9$ \\
\hline Poisson oranı (\%) & 0.2 & - \\
\hline
\end{tabular}

Tablo 3'deki veriler malzeme tedarikçilerinden temin edilmiştir. Şekil 2'de köprü kolonlarından alınan karotlar görülmektedir. Köprü kolonlarından alınan 9 adet numuneden 3 tanesi standart karot numuneleri ayrıldıktan sonra kalan 6 numune epoksi yapıștırıcıyla yapışması için 3 gün bekletilerek, beton hava kurusu durumuna getirilmiştir. 3 gün bekletilen numunelerin yüzeyleri temizlenmiștir. Epoksi esaslı astar A (karışım miktarı:2,76 kg) ve B (karışım miktarı:1,24 kg) tipi 3 dakika boyunca karıştırıldıktan sonra numunelerin dış yüzeyine sürülüp 
1 saat kurumaya bırakılmıștır. Ardından epoksi A tipi(karışım miktarı:3,73 kg) ve B tipi (karışım miktarı:1,27 kg) karışım kuruyan astarın üzerine uygulanmıștır. Tek yönlü, lifli polimer kumaş tipi karbon elyaf numunelere sarılmıştır. Çift kat sargı uygulanan numuneler 3 kat tek sargılı numuneler 7 gün kurumaya bırakıldıktan sonra üzerine tekrar epoksi yapıștırıcı sürülerek bir kat daha karbon elyaf kaplanarak üretilmişlerdir. Şekil 2'de karot numunelerinin karbon elyafla kaplanma aşamaları ve basınç dayanımı uygulanması görülmektedir.

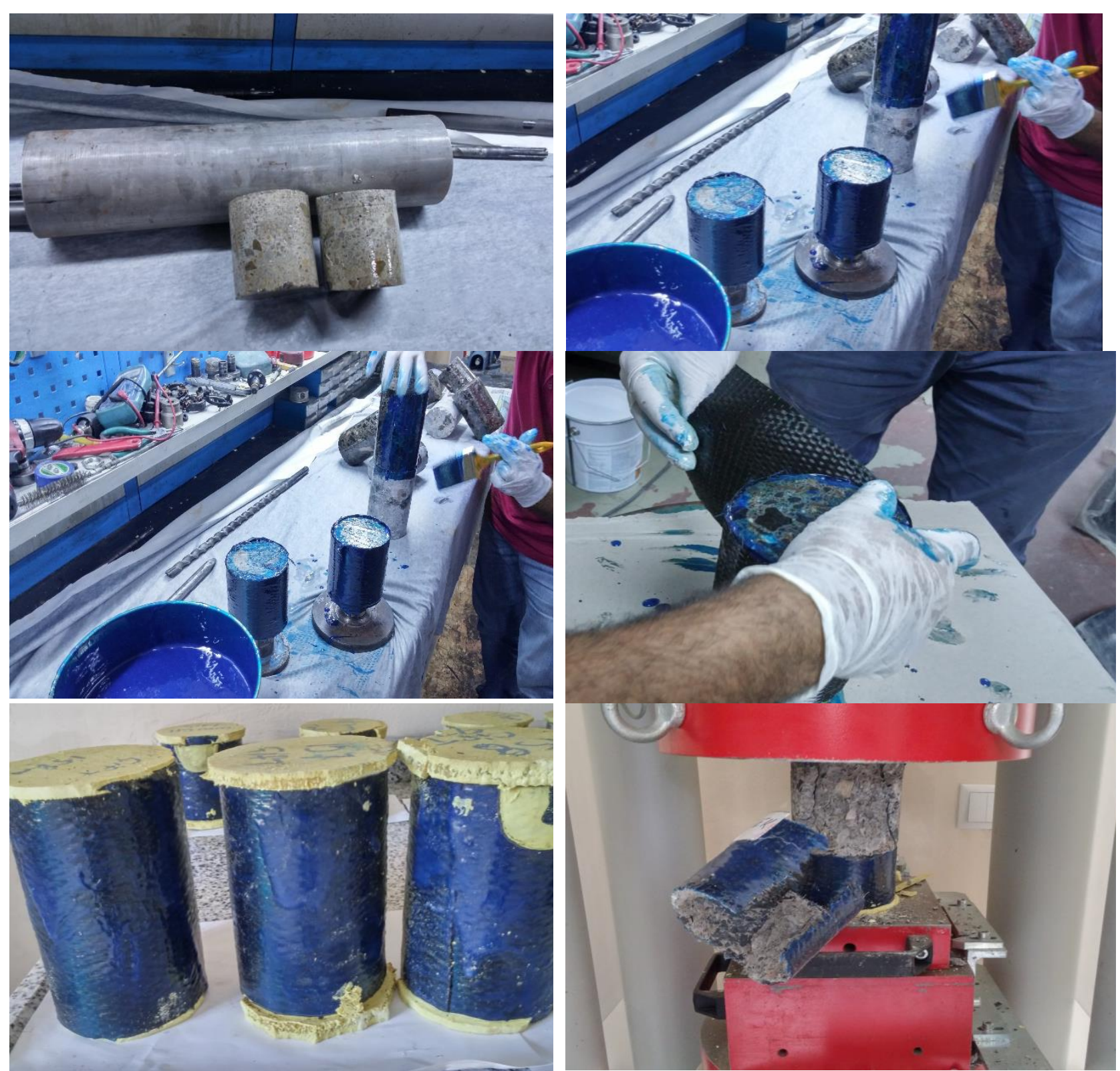

Şekil 2. Numunelerin CFRP kaplama ve basınç deneyine tabi tutulma aşamaları (Stages of Subjecting Samples to CFRP Coating and Pressure Testing)

\subsection{Ansys Analiz ve Modelleme (Ansys Analysis and Modelling)}

Basınç dayanımı testine tabi tutulan karot numuneler Ansys Workbench v17.2 sonlu eleman paket programında Şekil 3'de verilen boyutlarda modellenmişlerdir.

Modelleme yapılırken betonun nonlineer özelliklerini dikkate almak için Ansys Workbench paket programı malzeme kütüphanesinde bulunan Drucker-prager malzeme parametreleri kullanılmıştır. Așağıda Tablo 4'de kullanilan betonun lineer ve nonlineer parametreleri verilmektedir. 


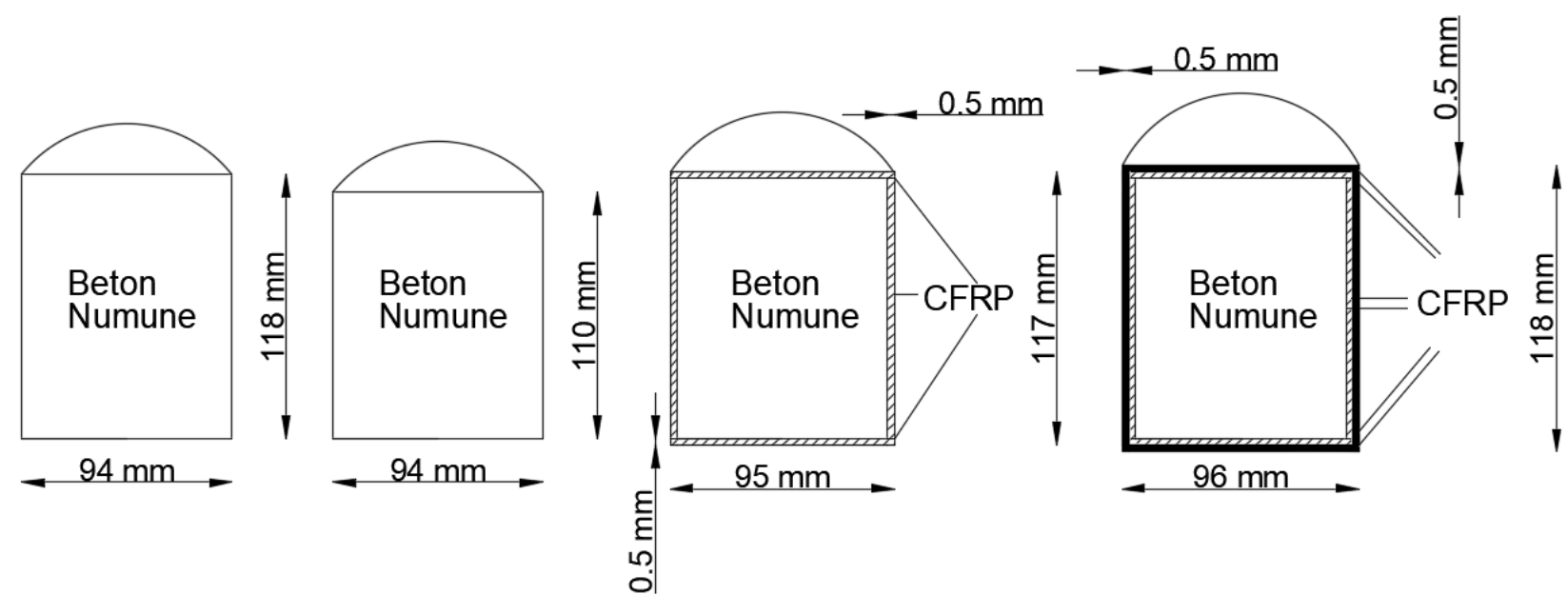

Şekil 3. Karot numunelerinin Ansys Workbench v17.2'deki modelleme boyutları (Modelling Dimensions of Core Samples in Ansys Workbench v17.2)

Tablo 4. Lineer ve Nonlineer Parametreler (Linear and Nonlinear Parameters))

\begin{tabular}{|c|c|}
\hline Lineer Parametreler & Değer \\
\hline Yoğunluk $\left(\mathrm{kg} / \mathrm{m}^{3}\right)$ & 2300 \\
\hline Elastisite Modülü (Pa) & $3 \mathrm{E}+10$ \\
\hline Poisson Oranı & 0.18 \\
\hline Hacim Modülü (Pa) & $1.5625 \mathrm{E}+10$ \\
\hline Kayma Modülü (Pa) & $1.2712 \mathrm{E}+10$ \\
\hline Nonlineer Parametreler (Drucker- Prager) & Değer \\
\hline Ölçek & 1 \\
\hline Öteleme (Pa) & 0 \\
\hline Maksimum Çekme Gerilmesi (Pa) & $-4 \mathrm{E}+06$ \\
\hline
\end{tabular}

Şekil 4'de kontakt tipleri ile ilgili bilgiler verilmektedir. Modelleme esnasında epoxy malzeme tanımlanmamış, CFRP malzemenin birbirine ve beton numunelere temas ettiği noktalarda kontakt tipi olarak bonded seçilmiştir. Bonded kontakt tipinde kullanılan geometrinin hem geometri ekseni hem de geometri eksenine dik doğrultuda yer değiştirmediği kabul edilmektedir.

\section{NORMAL DIRECTION BEHAVIOUR}

Contact TARGET CONTACT PAIR CAN SEPARATE OUT

\section{Contact}

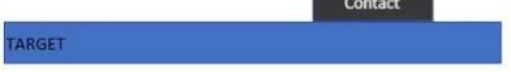

Contact

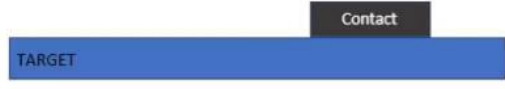

\section{Contact}

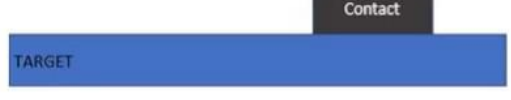

TANGENTIAL DIRECTION BEHAVIOUR

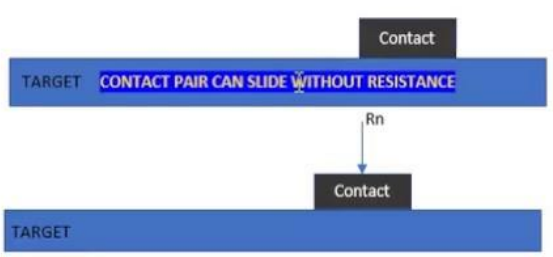

Contact

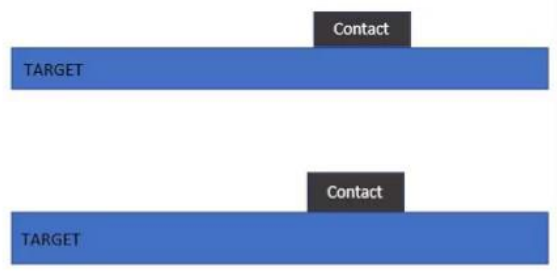

Details of "Bonded - SYSISolid To SYSISolid" Scoping Method Geometry Selection Contact \begin{tabular}{l} 
Target \\
\hline Contact Bodies \\
\hline Brget Bodes
\end{tabular} Target Bodies Definition Scope Mode \begin{tabular}{|l|}
\hline Scope Mode \\
\hline Behavior \\
\hline
\end{tabular} Trim Contac Suppressed
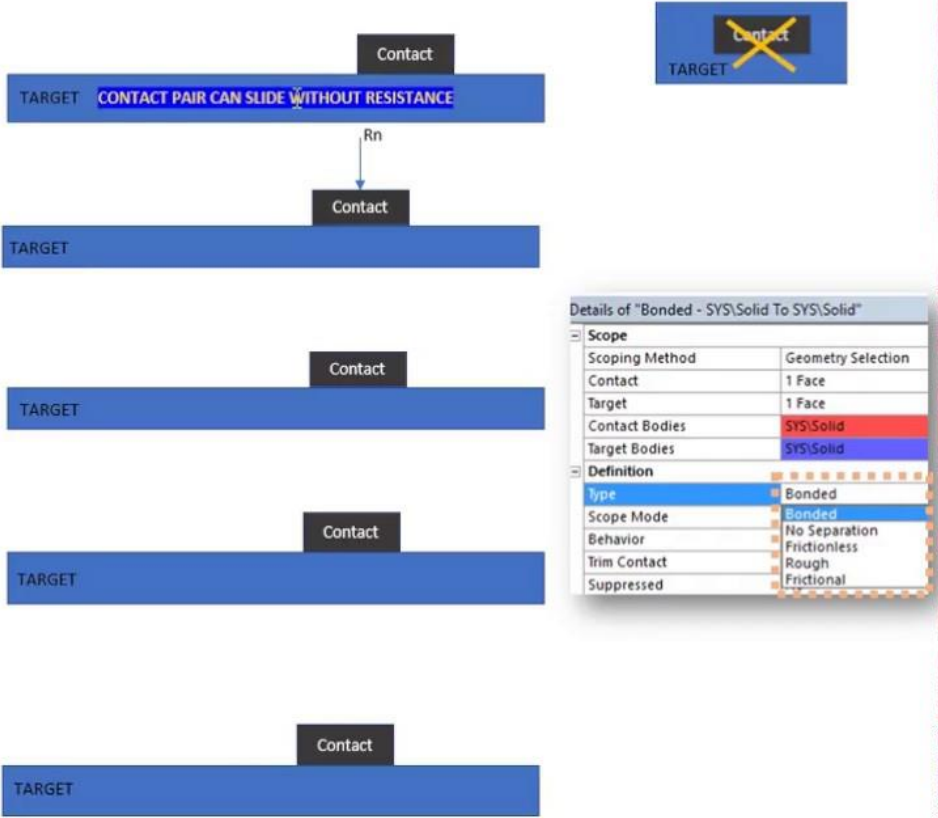

Şekil 4. Temas Tipleri (Contact Types) (URL-1) 
Analiz esnasında yük olarak numunelerin tek eksenli basınç deneyinden elde edilen kırılma yükü -Z ekseninde numunenin üst düzlemine etkitilmiştir. Etkitilen kırılma yükü aşağıdaki Tablo 5 ve Şekil 5'de verilmiştir.

Tablo 5. Numunelerin Analizlerdeki Kırılma Yükleri (Failure Loads of Samples in Analysis)

\begin{tabular}{|c|c|c|c|}
\hline Numune Kodu & Çap (mm) & Yükseklik (mm) & Kırılma Yükü (kN) \\
\hline K-SRGSZ1 (CFRP siz) & 94 & 118 & 168.60 \\
\hline K-SRGSZ1 (CFRP siz) & 94 & 110 & 178.00 \\
\hline K-TKSRGL1 (Tek Kat CFRP) & 95 & 117 & 357.40 \\
\hline K-ÇFTSRGL1 (Çift Kat CFRP) & 96 & 119 & 488.20 \\
\hline
\end{tabular}

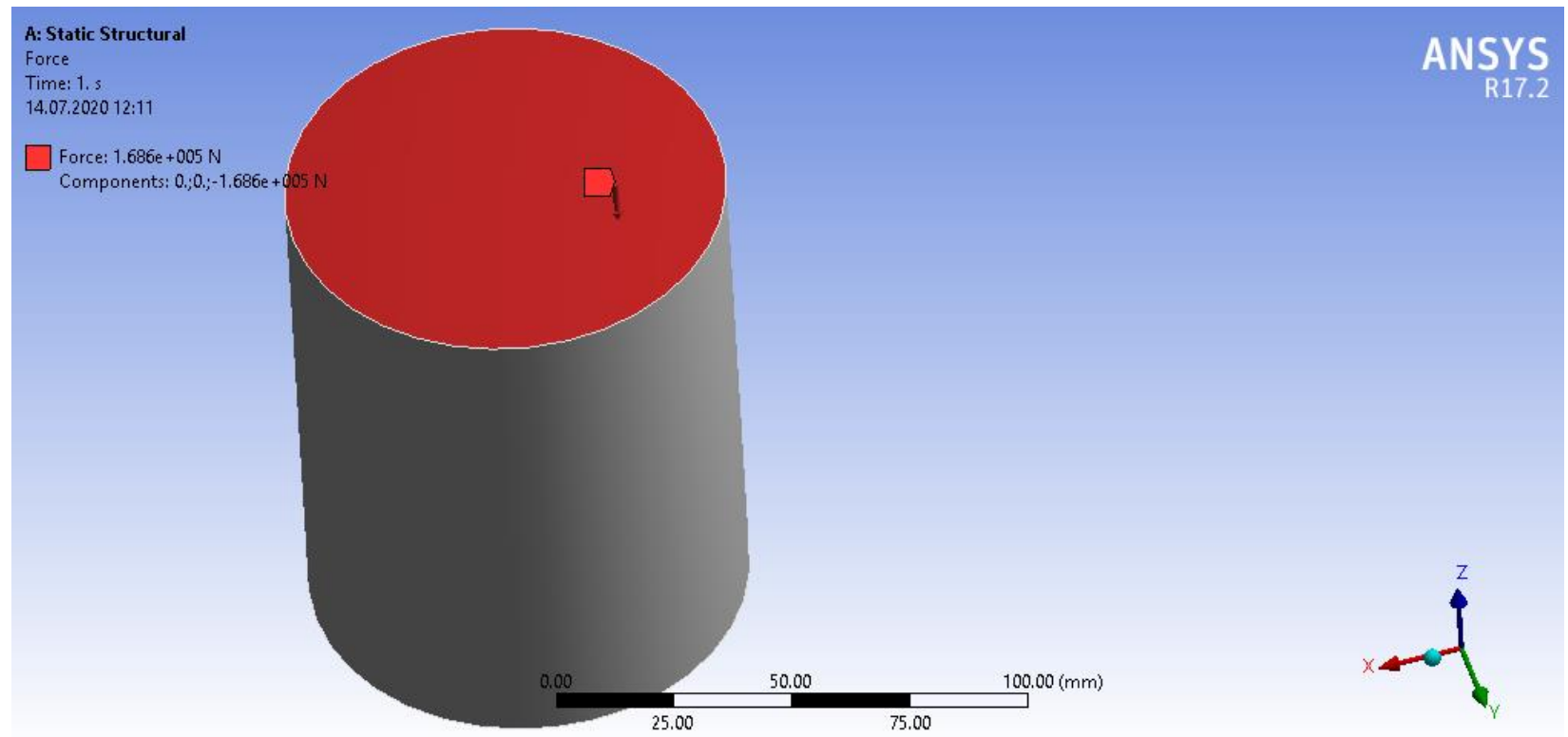

Şekil 5. Numunelere -Z ekseninde uygulanan yük (Load Applied to -Z Axis) (Ansys Workbench V17.2)

Sonlu elemanlar yönteminin doğru ya da kabul edilebilir sonuçlar verebilmesi için sonlu eleman diğer bir deyişle mesh kalitesi önemli bir yer tutmaktadır. Mesh boyutu yer değiștirmeleri çok etkilememesine rağmen yer değiştirmenin dördüncü derece türevi olarak ifade edilebilen gerilmelerde hata oranı kümülatif olarak artmaktadır. Bu nedenle doğru ve kabul edilebilir gerilme sonuçları için küçük mesh boyutları kullanmak doğru bir tercih olacağı öngörülmektedir. Ayrıca kullanılan numuneler dairesel olduğundan dolayı hekzagonal mesh seçeneği kullanılması uygun görülmüştür. Bu çalışmada karot numuneler Şekil 6'da görüldüğü gibi mesh edilip maksimum mesh boyutu olarak 2 mm, ortalama mesh kalitesi ise yaklaşık olarak \%87 kullanılmıștır.

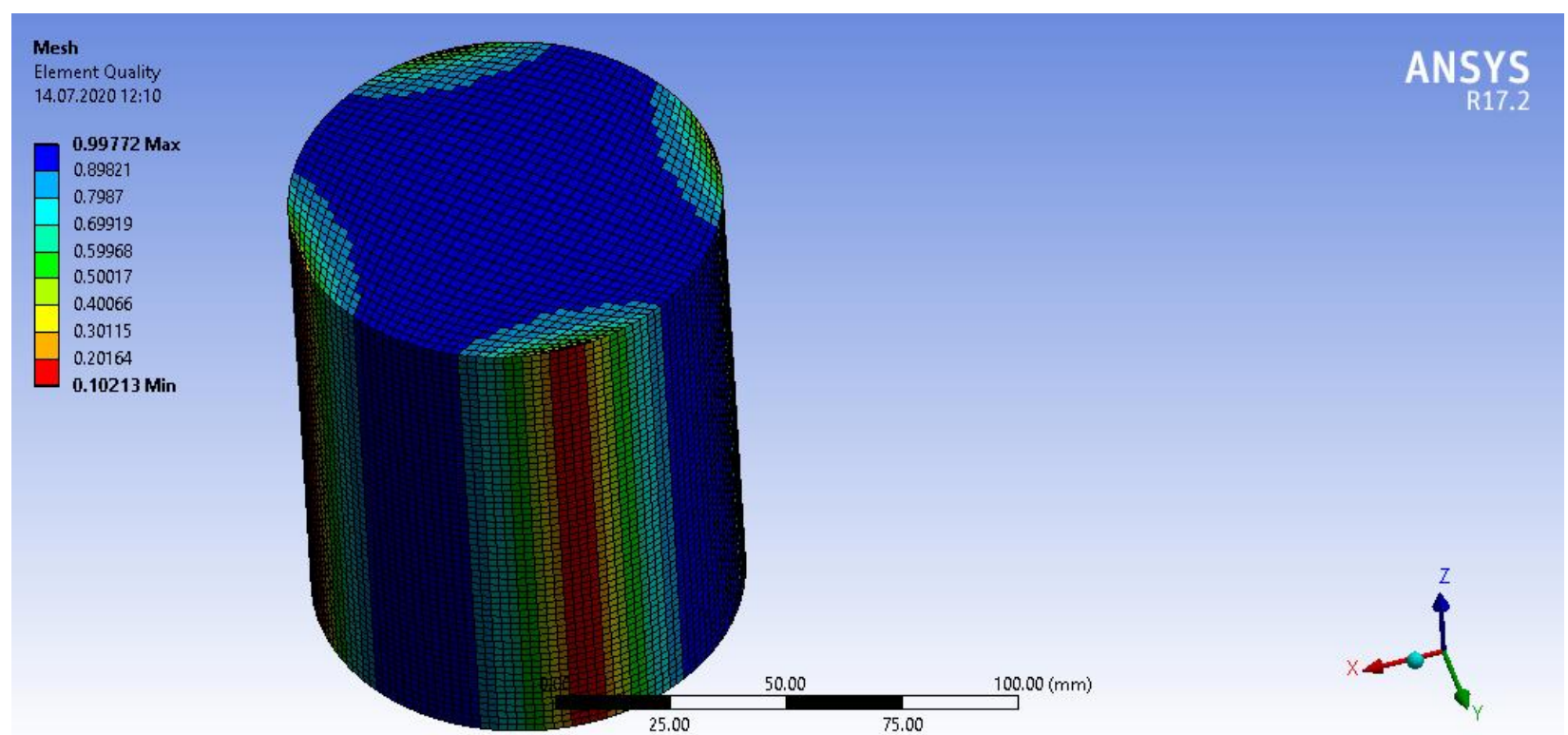

Şekil 6. Mesh kalitesi (Mesh quality) (Ansys Workbench V17.2) 


\section{Bulgular(Experimental Results)}

Bu çalışmada Ferhatlı - Gümüşhane Köy Yolu üzerindeki İncesu köprüsü sertleşmiş betonundan alınan 100mm anma çapa sahip 3'er adet numuneye ait ortalama basınç dayanımları Şekil 7'de görülmektedir.

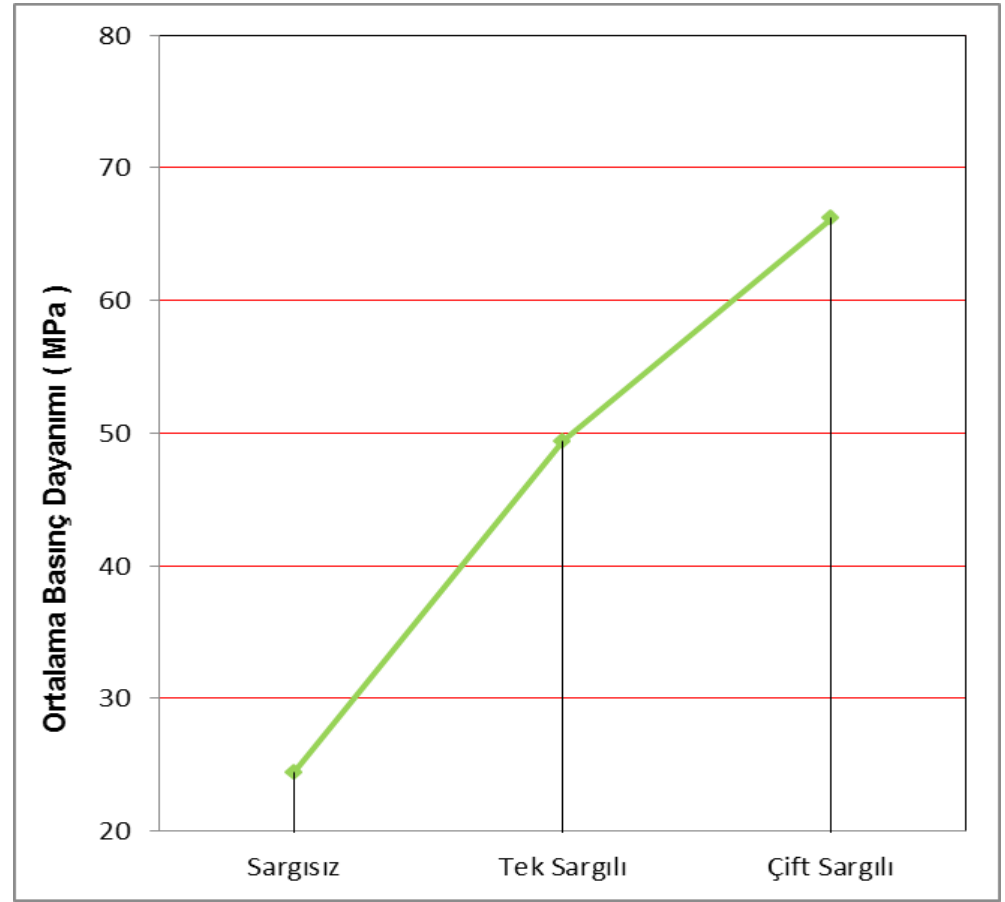

Şekil 7. İncesu Köprüsünden Alınan Karot Numunelerin Ortalama Basınç Dayanımları (Average Compressive Strengths of Core Samples Taken from İncesu Bridge)

Şekil 7'de İncesu Köprüsü beton imalatlarından alınan karot numunelerin ortalama basınç dayımı 24,8MPa olarak ölçülmüştür. Tek sargı karbon elyaf ve çift sargılı karbon elyaf kaplanması beton basınç dayanımını artırmaktadır. Şekil 8'de Ansys analiz programında modellenmiş çift sargı CFRP sargılı karot numunelerinde elde edilen numunelerdeki basınç gerilim dağılımı görülmektedir.

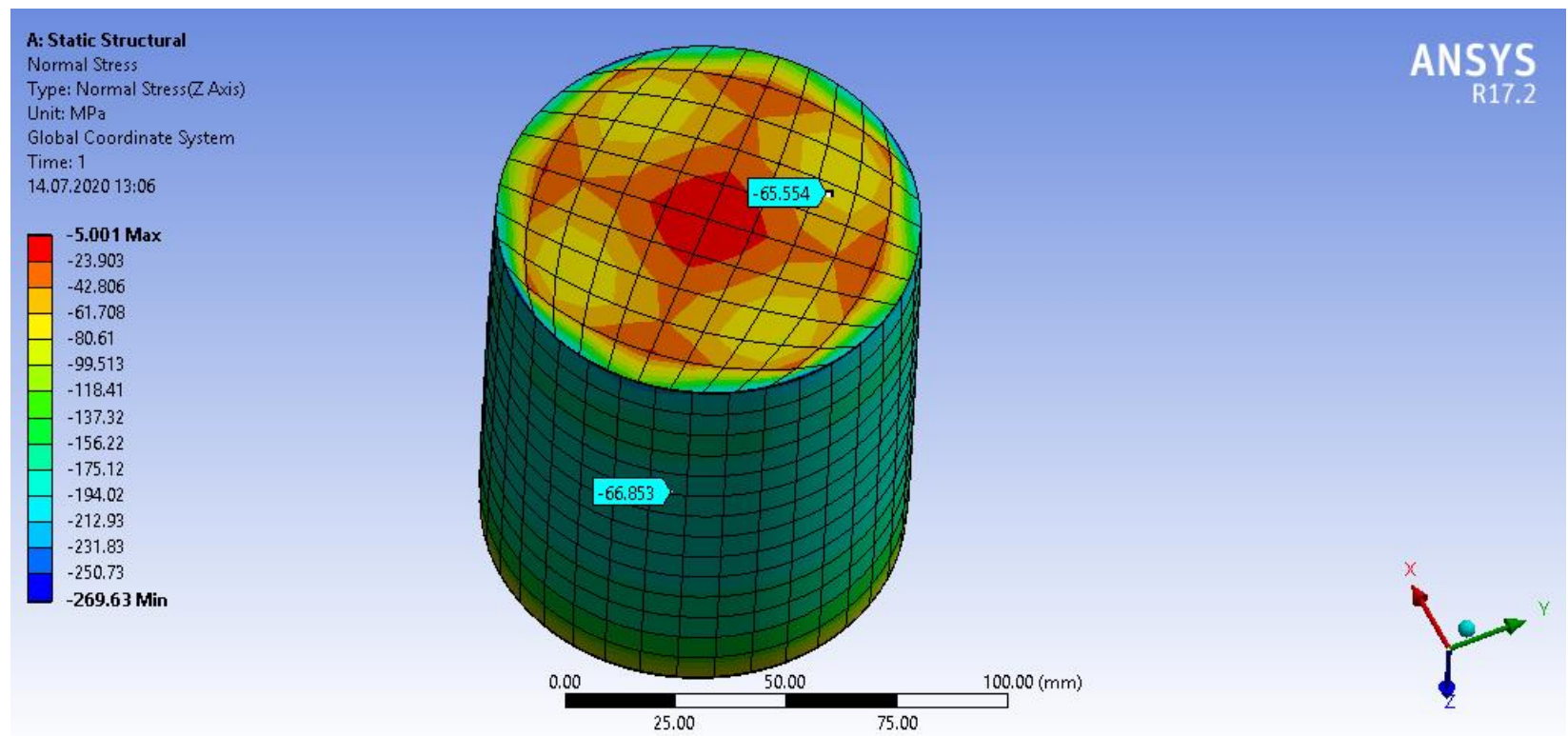

Şekil 8. Çift kat CFRP sargılı analiz modeli üzerinde gerilme dağılımları (Stress Distributions on Double CFRP Wrapped Analysis Model) (Ansys Workbench V17.2)

Tablo 6'da Ansys Workbench v17.2 sonlu eleman paket programında elde edilen basınç ve sayısal basınç dayanımları ile deneysel basınç dayanımları arasındaki oransal farklar görülmektedir. 
Tablo 6. Analiz ve deney sonuçlarının karşılaștırılması (Comparison of Analysis and Experimental Results)

\begin{tabular}{|c|c|c|c|}
\hline Numune Kodu & Ansys (MPa) & Deney (MPa) & Rölatif Hata (\%) \\
\hline K-SRGSZ1 (CFRP siz) & 24.5 & 24.8 & 1.2 \\
\hline K-TKSRGL1 (Tek Kat CFRP) & 47.9 & 49.4 & 3.04 \\
\hline K-ÇFTSRGL1 (Çift Kat CFRP) & 65.5 & 66.2 & 1.06 \\
\hline
\end{tabular}

Deneysel karot numuneleri basınç dayanımları ile sayısal olarak hesaplanan basınç dayanımları arasında \%1 ile \%3 arasında değişen farklar görülmektedir.

\section{Tartışma ve Sonuç (Discussion and Conclusion)}

$\mathrm{Bu}$ çalışma kapsamında sargısız, tek kat CFRP sargılı ve iki kat CFRP sargılı silindir beton numunelerin basınç dayanımları deneysel ve sayısal olarak karşılaştırılmıştır. Çalışmada karot alınan sargısız numunelerin ortalama basınç dayanımı 24,8MPa olarak elde edilmiștir. Sargısız numunelere 0,5 mm kalınlığında epoksi ile tek yönlü CFRP kumaş sargı takviyesi yapıldı̆̆ında ortalama numune dayanımının \%95 artışla 49.4MPa'ya çıktığı görülmüştür. Çift kat (toplam 1mm) sargı uygulandığında ise basınç dayanımının sargısız numuneye oranla \%167 artışla 66.2MPa'ya ulaştığı görülmüştür. Bu çalışmada elde edilen değerler literatürde benzer çalışmalarla karşılaştırıldığında birbirleriyle tutarlı sonuçlar olduğu görülmektedir (Liv d., 2020). Literatürde bu konuyla ilgili birbirinden farklı değerler elde edilmiş ve tek kat sargı için \%100'e varan iki kat sargı içinse \%200'e varan dayanım artıșı elde edilmiștir. Elbette bu artıș sargı malzemesinin özelliklerine, numunelerin boyutlarına, beton kalitesine ve uygulanan yüklemeye göre değişiklik göstermiştir. Bununla birlikte yapılan araştırmaların çoğunda 150x300 mm standart silindir numune boyutları tercih edilmiştir. Bu boyutlar için CFRP güçlendirme ile kazanılan dayanım artışında literatür ortalaması tek kat sargı için \%25, çift kat sargı içinse \%50 civarındadır (Çelik ve Karaşin, 2014; Lam ve Teng, 2009; İlki vd., 2003; ). Bazı çalışmalarda ise \%100'ü aşan dayanım artış değerleri elde edilmiştir (Adibelli vd., 2017). Literatürdeki farklı sonuçlar birçok sebebe bağlanabilir. Kullanılan polimerin özellikleri başta olmak üzere güçlendirilen elemanın boyutları ve beton sınıfı gibi faktörler de dayanım artışını etkilemektedirler. Standart numunede beton dayanım sınıfı azaldıkça CFRP sargının etkisi daha hissedilir olabilmektedir. Bir diğer etkense numunelerin çap ve boylarıdır. Numune çapı arttığında sargı etkisi nispeten azalmaktadır. Numune boyu arttıkça da sargı etkisinde azalma beklenebilir. Örneğin Sarıbıyık, (2017) yaptı̆̆ı çalışmada 150x300mm boyutlarındaki silindir numuneleri tek kat ve çift kat CFRP sargı ile güçlendirmiştir. 30MPa olan standart numune dayanımının tek kat sargı ile \%67'lik artışla 50MPa'ya yükseldiği; çift kat CFRP sargıda ise \%113'lük artışla 64MPa'ya yükseldiği görülmüştür (Sarıyıbık, 2017). Bu çalışmada kullanılan silindir numunelerin çapları 94mm ve boyları 110-120mm aralığındadır. Bu boyutlar için elde edilen dayanım artış değerlerinin literatür ortalamasının üzerinde olması beklenen bir durumdur.

Çalışma kapsamında elde edilen deneysel veriler Ansys programıyla bilgisayar ortamında modellenerek elde edilen Tablo 6'deki veriler; tanımlanan bilgisayar modellerinin \%1-3 hata payıyla deneysel verileri doğruladığını göstermektedir. Nonlineer malzeme özellikleri ve katı cisimler arası temas problemleri dikkate alındığında elde edilen değerler oldukça yaklașık sonuç vermektedir (Yaylacı vd., 2019). Bu durum laboratuvar ortamında çok sayıda deney numunesi üretilerek elde edilecek deneysel verilerin bilgisayar ortamda çok daha kolay ve kısa sürede elde edilebileceğini göstermektedir.

Bu çalışmada aşağıdaki sonuçlar elde edilmiştir;

1- Betona epoksi ile CFRP sargısı basınç dayanımını artırmaktadır.

2- Bu çalışmadaki özellikte ve boyutlarda bir beton numunesinin basınç dayanımında tek sargı ile \%64'e, çift sargı ile \%167'e varan oranlarda basınç dayanımı artışı elde edilebilmektedir.

3- Betona CFRP sargısı numune kesit boyutlarında çok az miktarda artışa yol açmasına rağmen basınç dayanımlarını önemli oranda artırmaktadır.

4- Ansys programıla uygun modelleme yaklaşımı ile deneysel olarak elde edilen değerlere oldukça yakın basınç dayanım değerleri elde edilebilmektedir.

5- Bu çalışmada önerilen modelleme yaklaşımı CFRP sargılama ile gerçekleştirilecek güçlendirme projelerinde kullanılabilir bir yöntemdir. Böylece güçlendirilecek yapının ve taşıyıcı sistem elemanlarının CFRP sargı sonrası dayanım değerlerinin hesaplanabileceğini ortaya koyulmuştur.

\section{Teşekkür (Acknowledgement)}

Bu çalışma T.C Devlet Su İşleri Genel Müdürlüğü (DSİ) Artvin beton laboratuvarlarında gerçekleştirilmiştir. Desteklerinden dolayı tüm kurum çalışanlarına teşekkür ederiz. 


\section{Çıkar Çatışması (Conflict of Interest)}

Yazarlar tarafından herhangi bir çıkar çatışması beyan edilmemiştir. No conflict of interest was declared by the authors.

\section{Kaynaklar (References)}

Adibelli, H., Unal, I., Varisli, M. (2017). Karbon elyaf ve cam elyaf kumaș ile sargılı betonların eksenel basınç altında davranıșı, 20. ULUSAL MEKANIK KONGRESİ, 05 - 09 Eylül, Uludağ Üniversitesi, Bursa.

Baki, V. A. , NAYIR, S., ERDOĞDU, S.., \& Ustabas, I., (2020). Determination of the Pozzolanic Activities of Trachyte and Rhyolite and Comparison of the Test Methods Implemented. INTERNATIONAL JOURNAL OF CIVIL ENGINEERING.

Çelik, V. C.., Karaşin, H., (2014). Karbon Elyaf İle Betonun Güçlendirilmesi, Dicle Üniversitesi Mühendislik Fakültsi Mühendislik Dergisi, Cilt 5, Sayı 1, sayfa 1-11.

Dilmaç, H., Ulutaș, H., Tekeli, H., \& Demir, F. (2018). An Evaluation on Seismic Performance of Existing Reinforced Concrete Buildings in Turkey. Mehmet Akif Ersoy Üniversitesi Fen Bilimleri Enstitüsü Dergisi, 9(Ek (Suppl.) 1), 224-237.

Dilmaç, H. (2020). Preliminary assessment approach to predict seismic vulnerability of existing low and mid-rise RC buildings. Bulletin of Earthquake Engineering, 1-33. Mechanics, 75(2), 211-227.

Eid, R., Paultre, P., (2017). Compressive behavior of FRP-confined reinforced concrete columns,Eng. Struct., vol. 132, pp. 518530.

Gurbuz, A. Tekin, M., 2017. Developing Damage Estimation Methods for Different Types of Reinforced Concrete Buildings, TEKNIK DERGI, vol.28, pp.8051-8076.

Hiçyılmaz, Ö , Özçelik, M . (2019). Ankara - Sivas Demiryolu Hizli Tren Projesi T-5 Tüneli Yapim Çalişmalari . Mühendislik Bilimleri ve Tasarım Dergisi , 7 (2) , 321-329. DOI: 10.21923/jesd.491825.

Ilki, A., Kumbasar, N., Koç, V., (2003). Low and medium strength concrete members confined by fiber reinforced polymer jackets, ARI Bull. Istanbul Tech. Univ., vol. 53, no. 1.

İlki, A., Kumbasar, N., (2002). Karbon Lif Takviyeli Polimer Kompozit Malzeme ile Hasarlı Betonarme Elemanların Onarım ve Güçlendirilmesi, İMO Teknik Dergi, s. 2598-2616.

Ilki, A., Peker, O., Karamuk, O., Demir, C., Kumbasar, N., (2008). FRP Retrofit of Low and Medium Strength Circular and Rectangular Reinforced Concrete Columns. Mater. Civ. Eng., vol. 20, no. 2, pp. 169-188.

Karaşin, H., Öncü, M., Yılmaz, S., (2010). Cfrp İle Güçlendirilmiş Kesitlerin Tekrarlanan Yükler Altındaki Davranışı. E-Journal of New World Sciences Academy, 5(3), 130613114.

Kurt, Z., \& Ateş, S.., (2019). Sismik İzolasyonlu Betonarme Bir Köprünün Dinamik Analiz Yöntemlerinin Kesit Tesirlerine Etkisi . 4. Köprüler ve Viyadükler Sempozyumu.

Lam, L., Teng, F. G., (2009). Stress-strain model for FRP-confined concrete under cyclic axial compression," Engineering Structures, 11(2) 308-321.

Lee, D.H., Han, S.J., Kim, K.S., LaFave, J.M. (2017). Shear strength of reinforced concrete beams strengthened in shear using externally-bonded FRP composites. Composite Structures 173, 177-187.

Li W.,, Tang S.,, Huang Z., Yang X., Shi T., Xing F., (2020) Shear behavior of concrete beam reinforced in shear with carbon fiber reinforced polymer mesh fabric (CFRP-MF) configuration, Engineering Structural, 218, 110828

Mert, N., Elmas, M. (2007). Fiber Takviyeli Polimerle Güçlendirilen Betonarme Kirişlerin Doğrusal Olmayan Analizi, Uluslararası Deprem Sempozyumu, Kocaeli.

Mirmiran, A. Shahawy, M., (1997). Behavior of Concrete Columns Confined by Fiber Composites, J. Struct. Eng., vol. 123, no. 5, pp. 583-590.

Vincent, T., Ozbakkaloglu, T., (2016). Influence of overlap configuration on compressive behavior of CFRP-confined normaland high-strength concrete. Mater Struct 49, 1245-1268. https://doi.org/10.1617/s11527-015-0574-x.

Ozbakkaloglu, T., Lim, J. C., (2013). Axial compressive behavior of FRP-confined concrete: Experimental test database and a new design-oriented model," Compos. Part B Eng., vol. 55, 607-634.

Sarıbıyık, A., (2017). Betonların Güçlendirilmesinde FRP Kompozitlerin Hibrit Olarak Kullanımının Etkisi, Sakarya Üniversitesi Fen Bilimleri Enstitüsü Dergisi, 22 (2), 383-391.

Seffo, M., Hamcho, M., (2012). Strength of concrete cylinder confined by composite materials (CFRP)," in Energy Procedia, vol. 19 , pp. 276-285.

Stolla, F., Saliba, J. E., Casper, L.E. (2000). Experimental study of CFRP-prestressed high-strength concrete bridge beams. Composite Structures, 49 (2) 191-200.

Tekeli, H., Dilmaç, H., Demir, F., \& Güler, K. (2020). Prediction of Seismic Performance of Existing Framed Reinforced Concrete Buildings. Journal of Performance of Constructed Facilities, 34(3), 04020030.

TS EN 12390-3, (2003). Beton - Sertleșmiş Beton Deneyleri - Bölüm 3 :Deney Numunelerinde Basınç Dayanımının Tayini, Ankara.

Turgay, T., Polat, Z., Koksal, H. O., Doran, B., Karakoç, C., (2010). Compressive behavior of large-scale square reinforced concrete columns confined with carbon fiber reinforced polymer jackets, Mater. Des., vol. 31, no. 1, pp. 357-364.

Ustabas, I., (2012). The effect of capillarity on chloride transport and the prediction of the accumulation region of chloride in concretes with reinforcement corrosion, Construction and Building Materials 28 (1), 640-647.

Ustabas, I., Desik, F., (2020). Transition coefficients between compressive strengths of samples with different shape and size in mass concrete and use of weight maturity method in dam construction. STRUCTURAL CONCRETE .

Xiao, Y., Wu, H., (2003). Compressive behavior of concrete confined by various types of FRP composite jackets," J. Reinf. Plast. Compos., vol. 22, no. 13, pp. 1187-1201.

Yaylacı, M , Bayrak, M , Avcar, M . (2019). Finite Element Modeling of Receding Contact Problem . International Journal of Engineering and Applied Sciences , 11 (4) , 468-475 . DOI: 10.24107/ijeas.646718. 
Yin, P., Huang, L., Yan, L., Zhu, D., (2016). Compressive behavior of concrete confined by CFRP and transverse spiral reinforcement. Part A: experimental study, Mater. Struct., vol. 49, no. 3, pp. 1001- 1011.

Zhong, Y. Z., Yu, Q., Tao, Z., (2008). Compressive behaviour of CFRP-confined rectangular concrete columns, Mag. Concr. Res., vol. 60 , no. 10 , pp. $735-745$ 